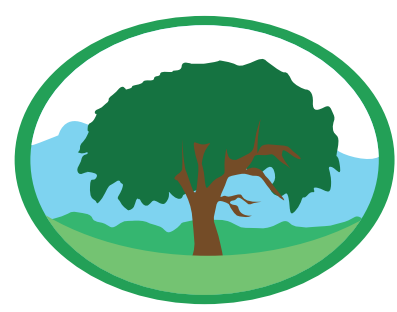

\title{
Criação de peças tridimensionais complexas a partir de impressora 3D compacta: Protótipos de um microgerador eólico
}

\author{
GARRÉ, S. O. ${ }^{1}$; ROSALES, J. L. L. ${ }^{1}$; JODAR,T. D. V. ${ }^{2}$; PETRY, A. P. ${ }^{3}$; VAGTINSKI,A. P. ${ }^{4}$ WWEYMAR, G. J. ${ }^{5}$; \\ 'Doutorando do Programa de Pós-Graduação em Engenharia Mecânica da Universidade Federal do Rio Grande do Sul \\ ${ }^{2}$ Mestrando do Programa de Pós-Graduação em Engenharia Mecânica da Universidade Federal do Rio Grande do Sul \\ ${ }^{3}$ Professora Programa de Pós-Graduação em Engenharia Mecânica da Universidade Federal do Rio Grande do Sul \\ ${ }_{4}^{4}$ Professor da Escola de Engenharia Mecânica da Universidade Federal do Rio Grande do Sul \\ ${ }^{5}$ Professor Centro de Engenharias Universidade Federal de Pelotas - CEng/UFPel
}

Palavras-Chave:Impressão

3D, Microgeradores eólicos,

Protótipos aerodinâmicos

\begin{abstract}
Resumo
Este trabalho apresenta a metodologia para confeccionar-se peças complexas a partir de uma impressora 3D compacta. Para tanto desenvolvem-se testes iniciais necessários para se conhecer o equipamento, descreve-se o tempo demandado para a prototipagem, apresentam-se as soluções para impressão remota, expõemse os custos (impressão in loco versus terceirização do serviço) e os resultados dos diversos testes. Para avaliar a qualidade da impressão resultante, projetam-se pás aerodinâmicas que originam dois protótipos de um microgerador eólico, os quais são expostos a escoamento de ar forçado em túnel aerodinâmico. 0 processo de impressão 3D administrado, consegue traduzir fidedignamente as características aerodinâmicas de uma pá eólica. Por esse motivo, os protótipos idealizados neste trabalho, auxiliam na tomada de decisão para o projeto e construção de um microgerador eólico que será concebido em escala real. Evidenciando a viabilidade de se utilizar impressoras compactas no desenvolvimento de projetos complexos. Após as análises de projeto, de prototipagem e dos testes, constata-se a viabilidade econômica do processo executado in loco, mesmo se for necessário a aquisição do equipamento 3D.
\end{abstract}

\section{Creation of complex three-dimensional parts from compact 3D printer: prototype of a wind microgenerator}

Keywords: 3D Printing, Wind Micro-generators, Aerodynamic Prototypes.

\begin{abstract}
This paper describes the methodology to fabricate complex parts, from a compact 3D printer. Therefore are initial tests necessary developed to meet the equipment, described the time needed for prototyping, solutions for remote printing are presented, the costs (printing on-site versus service outsourcing) and the results of the various tests are exposed.To assess the quality of the resultant print are aerodynamic designed blades that originate from two prototypes of a wind microgenerator which are exposed to forced air outflow in the Aerodynamic tunnel. The administered 3D printing process, is able to faithfully translate the aerodynamic characteristics of a wind blade. For this reason, the prototypes idealized this work, assist in decision making for the design and construction of a wind microgenerator that will be designed in real scale. Evidencing the viability of using compact printers in the development of complex projects. After the design reviews, prototyping and tests, is verified the economic viability of the process performed in situ, even if the acquisition of 3D equipment necessary.
\end{abstract}




\section{INTRODUC̣ÃO}

A primeira impressora 3D foi construída por Charles Hull em 1984 marcando sua expansão no mercado a partir do século XXI com o aumento da demanda por esse tipo de equipamento. Impulsionada, principalmente, pelos preços mais acessíveis em consonância com o aumento da capacidade computacional, criatividade humana e versatilidade de execução das impressoras. As quais, atualmente, são capazes de imprimir objetos que vão desde um simples utensílio doméstico até próteses, casas e inclusive bioimpressão, que significa a possibilidade de, no futuro, imprimir-se tecidos do corpo humano, ossos e órgãos (DEURSEN, 2013).

Dá-se o nome de Modelagem por Acumulação ao processo de fabricação aditiva realizado por estas impressoras, no qual um material é depositado sobre uma superfície, em sucessivas camadas, até que se obtenhao produtopreviamente projetado. Existem diversas formas de procedê-la (Fusão e Deposiçáo de Material - FDM, Estereolitografia - SLA, Processamento de Luz Direta - DLP, Sinterização Seletiva a Laser - SLS, Multi Jet, Impressão 3D Colorida)mudando entre elas o material utilizado e o modo construtivo das camadas (REISDORFER, 2016).

Os materiais mais comuns para o processo de adição, são comercializados na forma de filamentos (espessura 1,75 mm e $3 \mathrm{~mm}$ ) compostos de plástico ABS (Acrilonitrila Butadieno Estireno) ou PLA (Ácido Polilático). O primeiro é um tipo de polímero bastante rígido e leve, que apresenta um bom equilíbrio entre resistência e flexibilidade,já o segundo é um polímero biodegradável, feito com ácido lático (composto orgânico de função mista - ácido carboxílico e álcool) a partir de fontes renováveis (milho, mandioca, beterraba e cana-de-açúcar por exemplo) (SILVEIRA, 2016).

Vale ressaltar que a complexidadedo processo de impressão e qualidade da peça final (resolução) é diretamente proporcional ao custo. Sendo assim projetos de elevada complexidade e resoluçáo sáo sinônimos de maiores custos pelo maior gasto de tempo, de material, de eletricidade e de hora máquina (depreciação). Soma-se a esse fato que algumas impressoras, compactas e de menor resolução, são limitadas e não executam projetos de alta complexidade, necessitando para isso que se adquira um equipamento com capacidade elevada ou que se contrate os serviços de empresas especializadas. (FERNANDES et al.,2016).

O mercado atual foca em impressoras capazes de reproduzir peças simples, geralmente para lazer, decoração e brinquedos. No entanto quando se deseja precisão, como é o caso de protótipos, os equipamentos 3D ficam demasiadamente onerosos e só compensam para casos de altas produçóes(TAKAGAKI, 2012).

Por esse fato o objetivo deste estudo foi imprimir peças de alta complexidade a partir de uma impressora 3D de pequeno porte e com seção z (altura de impressáo) limitada. Após o processo de prototipagem concluído, testaram-se as peças para validar o método. No caso desse trabalho, o objeto de estudo foram dois protótiposde um microgerador eólico que após impressos necessitavamtraduzir realismo aerodinâmico,pois dariam luz à tomada de decisôes para a construçáo de um microgerador eólico em escala real, previsto no Projeto de Pesquisa intitulado Sistema para Microgeração Eólica com Eficiência e Segurança(ÁLY et al., 2015).

\section{MATERIAL E MÉTODOS}

Geralmente, na tecnologia antecessora às impressoras 3D, passava-se por um processo táo trabalhoso quanto fabricar a versão real de um produto. Afinal,para se produzir um protótipo, era preciso modelar-se a peça manualmente,produzir-se um moldeematerializá-lo tridimensionalmente com volume e profundidade.Após a difusão das impressoras no processo de prototipagem, o trabalho foi reduzido e, paralelo a isso, o tempo e o custo também se retraíram.

$\mathrm{Na}$ impressão 3D os objetos são dimensionados virtualmente e criados através da adição de camadas sobrepostas.A qualidade de execução desse processo somado às dimensôes da impressora expressam a sua capacidade na aplicaçãoem projetos complexos. Normalmente, quanto maior for a complexidade de um projeto, maior será o gasto com a prototipagem $3 \mathrm{D}$. No entanto, desde que se atente para alguns fatores, equipamentosde pequeno porte e baixo custo, podem 
ser capazes de gerar peças complexas com desejável resolução final e fidedignidade na prototipagem, mesmo que apresentem limitada capacidade de impressão (principalmente na dimensão $z$ das peças).

A seguir apresentam-se essas e outras características para tornar possível a geração de peças complexas através de uma impressora compacta.

\section{Criação do Projeto Virtual}

Ao se produzir uma peça tridimensional por intermédio de impressoras $3 \mathrm{D}$ faz-se necessário a produçãode um arquivo virtual gerado através de software CAD (Computer Aided Design), o qual utiliza um aplicativo de modelagem ou um scanner $3 \mathrm{D}$ para criar e/ou replicar um objeto.

No caso desse trabalho analisaram-se os artigos desenvolvidos por Acunha,(2006); Wenzel, (2007); Akwa; Horn; Teixeira; Pereira, (2010); Rocha, et al; Gregg; Ludwig,(2011); Song; Silva;Patriozotto(2012); Franco, (2013); Prado, (2016) e dimensionou-se os protótipos por intermédio de equacionamentos previstos nasTeorias do Elemento de Pá,da Quantidade de Movimentoe do Ótimo de Betz. Em seguida escolheu-se o modelo de perfil aerodinâmico, que para esse caso foi o NACA 0012 (VERDUM, 2013). De posse dessas informaçôesutilizou-se software CAD para gerar o projeto virtual (Figura 1A) e finalmente construíram-seos protótipos (Figura 1B) das duas turbinas eólicas (GARRÉ, 2015).

A.

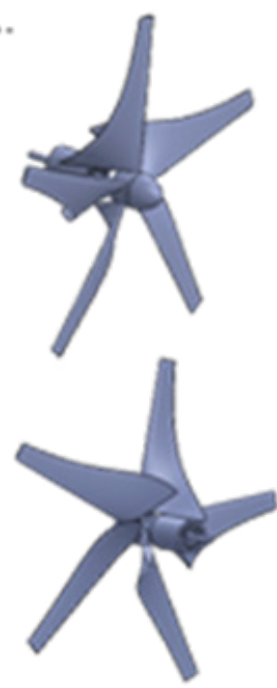

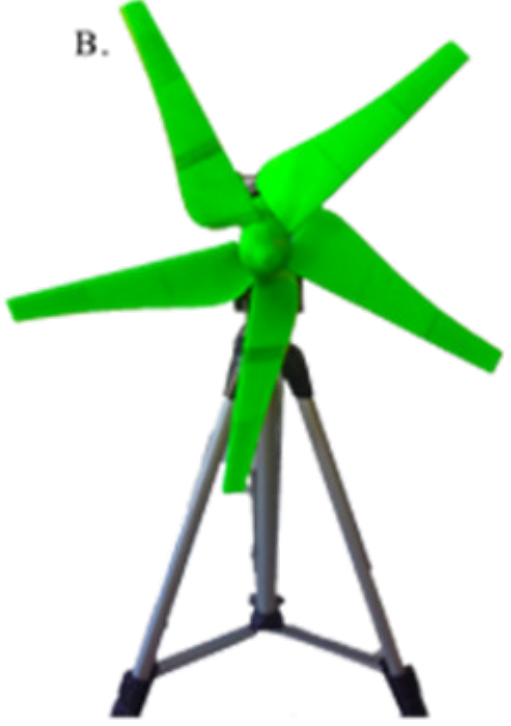

Figura 1. Protótipo: A.Projetado em CAD 3D; e B. Finalizado. Fonte: Adaptado de Garré, 2015
Para a geração dos dois protótipos foi necessário a criação de dez pás, dois centros e dois suportes do eixo.As pás possuíam dimensões diferentes, sendo que cinco foram projetadas obedecendo os comprimentos de corda $(C(r))$ (Pás Ótimas de Betz - POB) e cinco possuíam as cordas da base com dimensionamentos reduzidos (Pás Ótimas de Betz Modificadas - POBM).

Antes de começar o processo de fabricação das pás, ainda no ambiente virtual, fez-se necessário também seccioná-las em três partes iguais $(75 \mathrm{~mm})$ por uma limitação da impressora utilizada, que náo imprimia peças com altura superior a $100 \mathrm{~mm}$. Os encaixes do eixo e centros foram dimensionados proporcionalmente aos protótipos, sendo que os centros possuíamdimensóespré-estabelecidaspara que o produto final resultasse em protótipos de $500 \mathrm{~mm}$ de diâmetro (Figura 2).

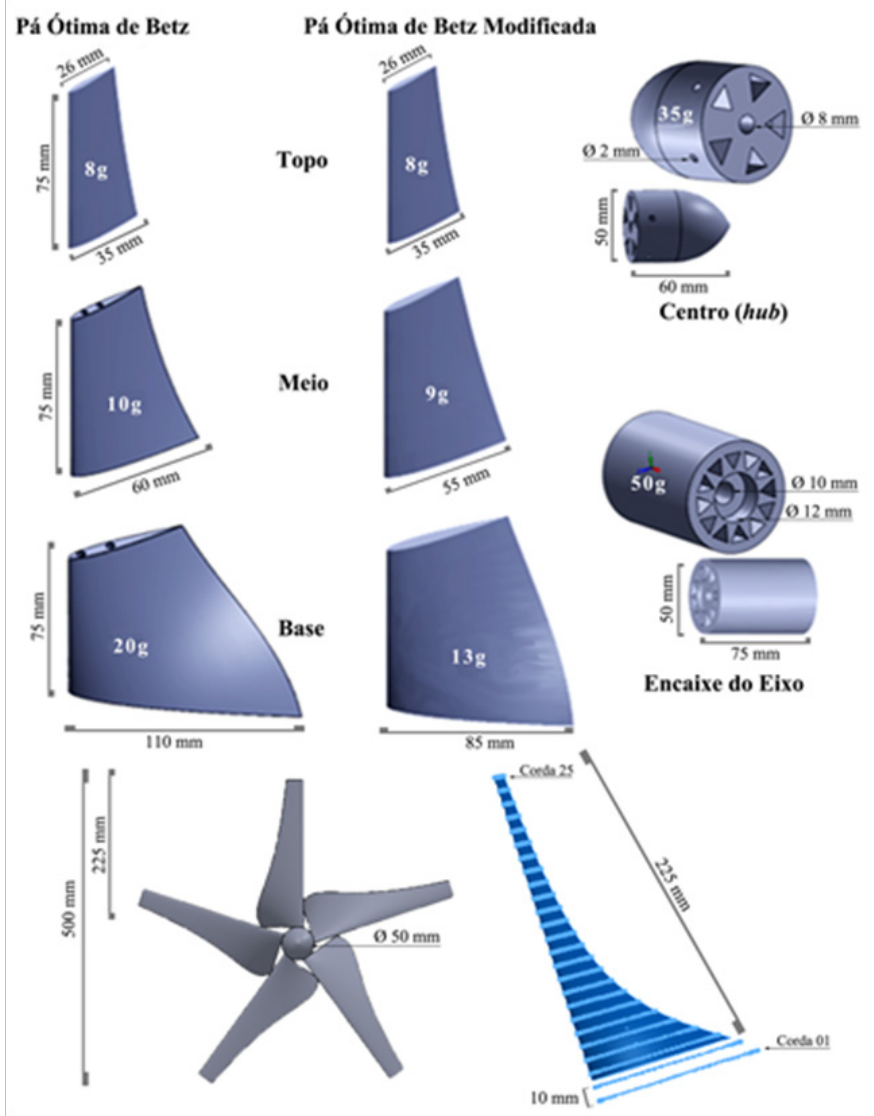

Figura 2. Detalhamento do projeto e dimensões das peças fabricadas. Fonte: Adaptado de Garré, 2015

As dimensôes dos protótiposforam obtidas através do descrito por Garréet al. (2015), o qual efetuou um estudo aerodinâmico que possibilitou a geração do projeto virtual por intermédio de equacionamentos previstos por Burton et al, 2001; Gasch e Twele, 2002. A partir dos resultados desse 
estudo obteve-se o dimensionamento da Corda do Perfil Aerodinâmico $(C(r))$, do Ângulo de Torção $(\beta(r))$, da Força de Sustentação $(d L)$,da Força de Arrasto $(d D)$, da Força Circunferencial $(d U)$; da Força Axial ou Empuxo $(d T)$, do Torque Estático(TWE)e as planilhas de resultado. Dados que foram indispensáveis para o desenvolvimento da análise apresentada nesse artigo.

\section{Processo de Prototipagem 3D}

Com o projeto virtual em mãos, partiu-se para $o$ processo de fabricação. Inicialmentea intenção era de terceirizar o serviço contratando empresas especializadas.Assim, efetuou-se um levantamento de preços e concluiu-se que essa opção apresentava um enorme potencial de inviabilizar o processo, pelo alto custo demandado. À procura de soluçôes, optou-se pelo desenvolvimento deestudos com uma impressora da marca Cliever CL1 (Figura 3) afim de diagnosticar a sua versatilidade e capacidade de produzir peças complexas.

O uso desta impressora foi disponibilizado gratuitamente pelo GMAp/NOTAq - Grupo de Mecânica Aplicada da UFRGS / Núcleo Orientado para Tecnologias Aquaviárias e suas características técnicas, de acordo com o fabricante, são:

- Dimensôes: Profundidade - 320 mm; Largura $320 \mathrm{~mm}$; Altura - $390 \mathrm{~mm}$;

- Área de impressão: $180 \mathrm{~mm}$ x $180 \mathrm{~mm}$ x 100 $\mathrm{mm}(\mathrm{x}, \mathrm{y}, \mathrm{z})$

- Mesa de impressão com controle de temperatura, variando de $0{ }^{\circ} \mathrm{C}$ até $190{ }^{\circ} \mathrm{C}$;

- Bico de extrusão com controle de temperatura variando de $0{ }^{\circ} \mathrm{C}-235^{\circ} \mathrm{C}$;

- Precisão de impressão: 100 mícrons a 300 mícrons ( 0,1 a $0,3 \mathrm{~mm})$;

- Software de controle: Cliever Lab (Pro);

- Imprime em PLA e ABS. Preferencialmente PLAde 3 mm.- Rolos de 1 kg;

A impressora utiliza a tecnologia de impressão 3D denominadaFusão e Deposição de Material (FDM). Utilizando como material de impressão o filamento plástico do tipo PLA. O processo é executado camada por camada, por meio de finíssimos fios de plástico os quais, através de repetição constroem os objetos (CLIEVER, 2015).

Em síntese, o processo de impressão analisado demandava que: se gerasse um arquivo 3D em algum software CAD que fosse reconhecido pelo software Cliever Lab (Pro) salvando-o no formato .STL; se submetesse o arquivo. STL criado, a um softwarede correção e reparo das peças; se importasse as peças reparadas para o Cliever Lab (Pro);se configurasse a impressora, calibrando-a quando necessário.

Finalizados esses passos preparava-se a bandeja de vidro e imprimia-se. Ao final do processo de impressão, esperava-se a bandeja de vidro esfriar e retirava-se a peça finalizada.

\section{Software}

Para a perfeita impressão na impressora estudada,

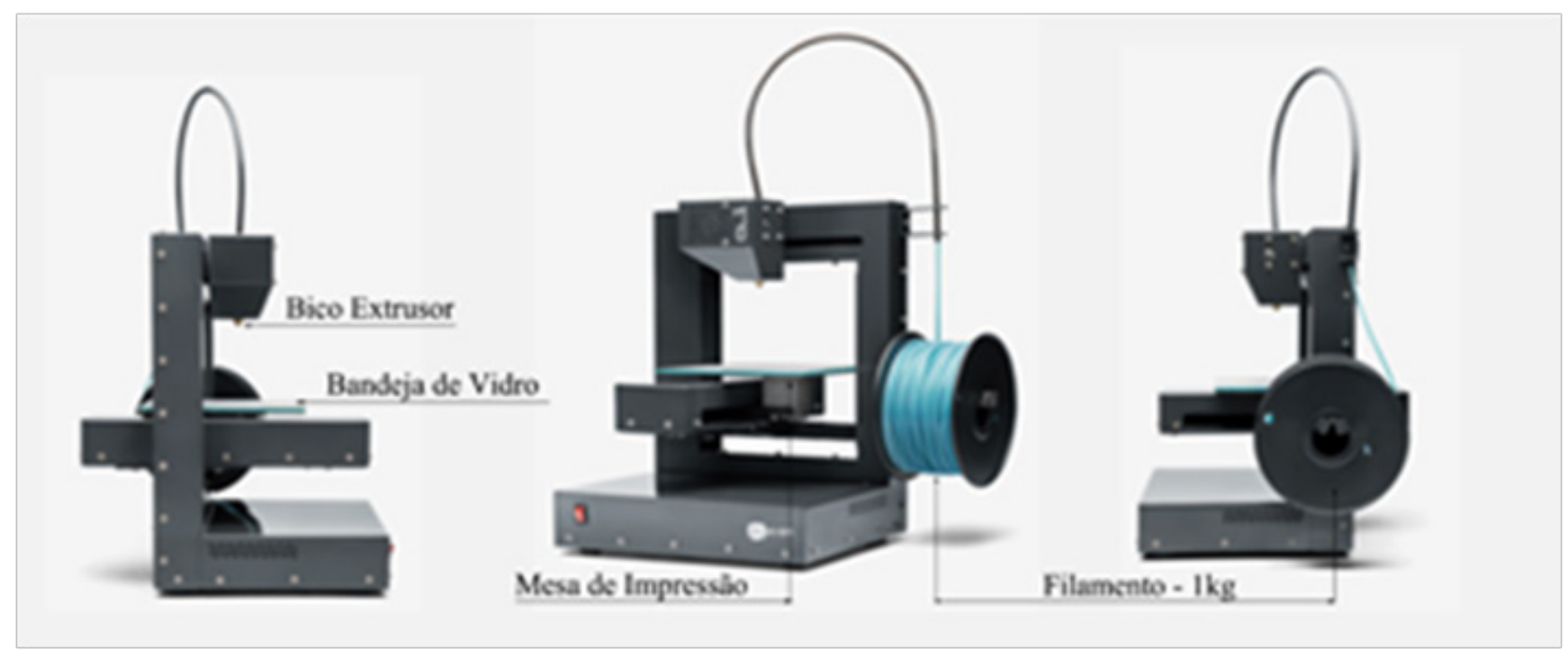

Figura 3. Impressora 3D Cliever CL1 


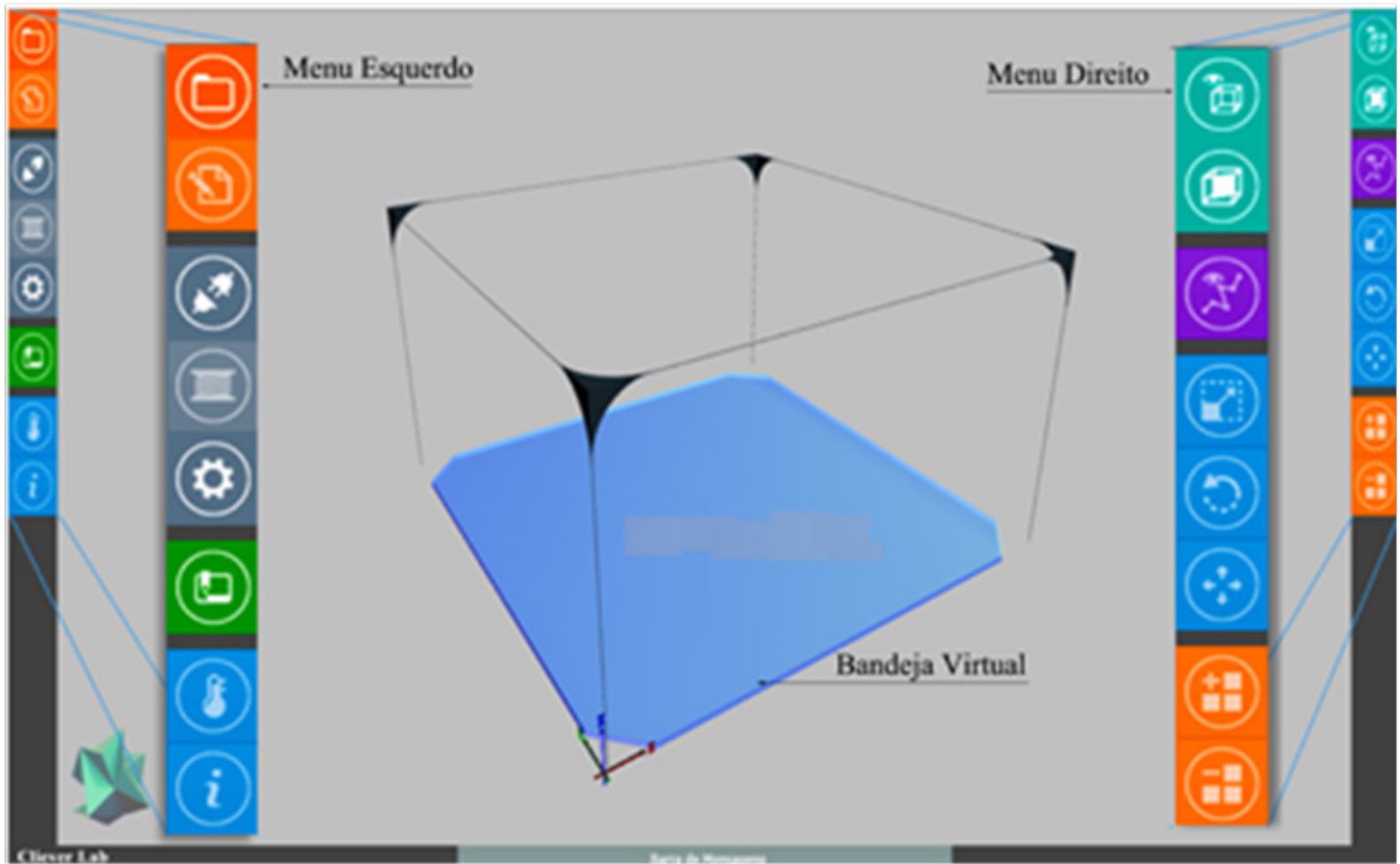

Figura 4.Área de trabalho do Cliever Lab (Pro)

fez-se necessário conhecer a fundo as características do seu software,com intuito de que se optasse pelas melhores configuraçóes de impressão.

A impressora escolhida apresenta características simples de fabricação, um design rústico e fácil manuseio. Seu software, o Cliever Lab (Pro), é dotado de diversos recursos que auxiliamna fabricação de peças de alto padrão e com desejável fidedignidade.

$\mathrm{Na}$ Figura 4 destaca-se a área de trabalho do softwareenfatizando-se seus dois menus.

Ao observar-se a Figura 4 o Menu Lateral Esquerdo apresenta, em ordem descendente:Abrir Seleciona o arquivo para área de impressão;Exportar - Permite salvar o modelo disposto na área de impressão; Conectar-Conecta e desconecta a impressora do software; Trocar Filamento - Permite efetuar a troca do filamento; Configuraçóes - Muda as preferências do tipo de impressão que se deseja;Definiçôes de Impressão

- Configuraçôes rápidas de impressão;Temperaturas - Informa as temperaturas da mesa e do extrusor; eInformaçóes - Tais quais como filamento gasto, tempo estimado, etc.

Já no Menu Lateral Direito, também em ordem descendente, têm-se:Opçôes de Visualização;Vistas Lateral, frontal, superior, isométrica, etc.;Visualizar
Percurso - Mostra o percurso que será seguido pelo bico extrusor;Redimensionar Sólido;Rotacionar Sólido;Movimentar Sólido;Duplicar Sólido; e Remover Sólido.

\section{Testes de configuração e tipos de filamentos}

Após conhecer-se osoftware e suas funcionalidades procederam-se testes alterando-se as configuraçóes de impressão e o tipo de material.

Primeiramente testou-se as configurações de fábrica da impressora imprimindo-se uma peça-teste. Para issoabria-se o software Cliever Lab (Pro), clicava-se na aba Abrir e selecionava-seo arquivo .STL(gerado no projeto virtual). Em seguida, afim de que se tivesseuma perfeita aderência do material extrusado,colocavasecola sobre a bandeja de vidro e fixava-a no suporte da impressora. Após escolhia-se as preferências de impressão na aba Configuraçôes,navegava-se até Definiçóes de Impressáoe na caixa que se apresentava, clicava-se em Imprimir. Podia-se antes de clicar em Imprimir, optar-sepor simular a impressão, com isso era possível saber a previsão do tempo de impressão, quanto de filamento seria gasto, entre outras coisas. Findado esse processo, removia-se o vidro da mesa, aguardava-se que o mesmo esfriasse e em seguida começava-se a remoção da peça impressa. 
Vale ressaltar que antes de começar o processo de impressão da peça criada em software CAD, o projeto virtual necessitavapassar por um software de correção de malha, haja visto que muitas das vezes os arquivos não eram corretamente finalizados. As pequenas arestas, que permaneciamem aberto na malha,prejudicavama leitura da impressora ocasionando erros e/ou pausas na impressão, o que por sua vez levava a perda completa de trabalhos, independentemente da fase em que a impressão se encontrasse, inutilizando as peças inacabadas. Para correção e fechamento de malhas a presente análiseutilizou o Netfabb, no entanto existem diversos programas que fazem o mesmo serviço.

Após testadas as configuraçôes de fábrica procederam-se novos testes mudando as preferências de impressão entre maiores e menores resoluçóes. Para tanto alteravam-se as configuraçôes deDensidade, Espessura das Paredes eAltura entre Camadas.A variabilidade destas configuraçóes foi amplamente debatida com o fabricante e testada com peças de diferentes geometrias. Também nessa análise imprimiram-se peças de mesma geometria com filamento do tipo ABS e PLA para decidir qual gerava o melhor produto final.

Objetivando reduzir o tempo demandado para a impressão de uma peça, analisou-se a possibilidade de se utilizar o volume dabandeja de impressão próximo a sua capacidade máxima. Para tanto foram necessários procedimentos de calibração e também ajustes manuais nos quatro parafusos damesa de impressão.

Para calibrar a impressora ligava-se o equipamentoconectando-o a um computador,em seguida abria-se o Cliever Lab (Pro) e clicavase em Conectar, navegava-se atéconfiguraçôes/ calibrare clicava-se em $O k$. No novo menu que se apresentava, determinava-se a medida necessária para evitar esmagamento ou desprendimento do material extrusado, aumentando-se ou reduzindo-se a distância entre o bico e a bandeja de vidro. Após esses ajustes clicava-se em próximo. Posterior a isso, preparava-se abandeja de vidro com colae a prendia na mesa de impressãocom grampos. Voltava-se ao software da impressora eclicava-se em simdando início ao processo de ajuste fino. A impressora iniciava o processo de impressão. Caso o produto gerado náo fosse um círculo perfeito, procedia-se corrigindo a altura do bico extrusor atentando para que não se gerasseesmagamento (bico muito próximo da bandeja de vidro) ou desprendimento (bico muito afastado da bandeja de vidro) do material extrusado. Após a correção da altura, clicava-se em salvar,finalizava-se o ajuste fino e imprimia-se as peças individualmente.

Após os testes de impressão individualiniciaramse os testes com a impressão de várias peças ao mesmo tempo, no entanto a calibração descrita não foi o suficiente para garantir a perfeita impressáo em todos os pontos da bandeja de impressão. Sendo assim,foi necessário ajustar-sea altura da bandeja de vidroapertando-se e afrouxando-se osparafusos que existiam nos cantos da mesa de impressão até que a impressão das peças se tornasse homogênea.

Pelo acúmulo de horas de trabalho demandadas, também foram feitostestes utilizando-se o artifício de acompanhamento remotoda impressáo. No caso desta análise escolheu-se o Team Viewer, que apresentava como principal característica a possibilidade de se conectar e controlar outros computadores virtualmente. Para tanto o software devia ser instalado no computador onde estava conectada a impressora (PC1) e também no computador que se desejava fazer o monitoramento à distância (PC2). Uma vez instalado, gerava-se uma id e senha. Isso faziase necessário para permitir a comunicação segura entre o (PC1) computador do Cliever Lab (Pro) e o (PC2) computador (notebook, tablete, celular, etc.) ligado em outro lugar (casa, serviço, cidade, etc.). Para efetuar a ligação remota entre PC1 e PC2 deviase primeiramente executar o TeamViewer no PC1, liberando-se o acesso para portadores de id e senha. Quando necessário entrava-se no PC2 e digitava-se os dados de acesso. Com essa conexão liberada era possível visualizar-se a área de trabalho do PC1bem como acessar pastas, programas edemais funcionalidades.

Após calibrada e configurada, a impressora geroupeças seccionadas de75 mm que,após impressas, foram unidas por intermédio de um pino metálico de $2 \mathrm{~mm}$ de diâmetro e cola de secagem rápida originando as pás de $225 \mathrm{~mm}$ dos protótipos. Estas, após montadas foram expostas a reagentes químicos e diversos outros tipos de materiais com a finalidade de 
promover-se testes de resistência e rugosidade.

Os testes de calibração e tipos de filamentosproduziram peças similares, as quaisforam submetidas aanálises de torque manual, resistência e rugosidade final,almejando-se que se tivesse a melhor relação entre o tempo de impressão e a qualidade/ funcionalidade do produto acabado. No totalforam impressas 86 peças, considerando-se as peças testes, as peças impressas por meio virtual, as peças reservas e os protótipos.Demandando, para isso, um montante de 200 horas de impressão.

\section{RESULTADOS E DISCUSSÃO}

\section{Configurações de impressão}

Para a melhor relação entre qualidade e tempo de impressão, após aproximadamente 80 horas de testes aliados a tutoriaise contato direto com a fabricanteaconselha-se que se mantenha as configuraçôes descritas na Figura 5, ou muito próximo disso, pois o aumento ou redução de alguns valores foram diretamente proporcionais ao tempo de impressão e custo final das peças.

A resolução final foi função do tempo, uma vez que ao configurar-se o software para Impressão de Alta Qualidade, a velocidade de impressão era reduzida.

O tempo de impressão também foi influenciado pela Densidade e pela Espessura das Paredes. $\mathrm{Na}$ primeira definia-se o preenchimento da peça, sendo assim o valor de $100 \%$ resultava numa peça totalmente sólida e $0 \%$ totalmente oca. Já na segunda definia-se a resistência e qualidade da peça, sendo diretamente proporcional ao número de camadas escolhidas.

Outro fato notado com o aumento demasiadodo tempo de impressão (períodos superiores a 40 horas) eraa chance de perda total do material impresso ocasionada por: erros no projeto e/ou nosoftware, interrupção no fornecimento de energia elétrica, deformação leve na base das peças, fim do filamento e desprendimento das peças. Por esse motivo o presente trabalho não administrou impressões ininterruptas que superassem às 30 horas.

\section{Filamento PLA versusfilamento ABS}

Para os testes com o ABS destinaram-se

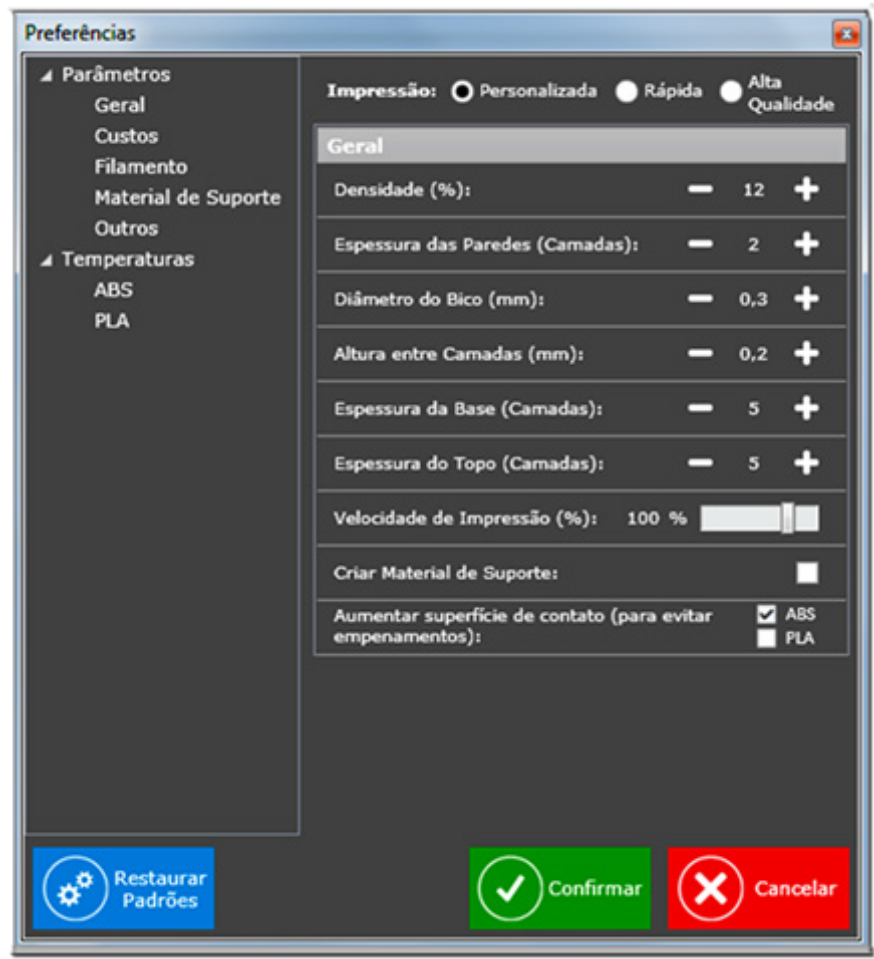

Figura 5. Configurações de impressão

aproximadamente 50 horas e com os testes do PLA foram utilizadas mais 30 horas. Esse total de 80 horas permitiu indicar qual filamento resulta em um melhor produto final.

Com o filamento do tipo ABS, não se conseguiu um bom produto final sem que se aumentasse em demasia o tempo de impressão. Acredita-se que o tempo de testes conduzidos com esse tipo de filamento foi insuficiente para concretizar as conclusóes. No entanto, durante o período de testes com esse tipo de filamento, nenhuma das peças prototipadas apresentaram uma boa resolução final. Por isso uma avaliação maior, com testes mais específicos, pode ser capaz de determinar com maior confiança se os problemas apresentados com o filamento do tipo ABS são gerados por falha do operador, pela qualidade do filamento, por limitação da máquina utilizada ou outro fatorimplícito.

Já com o filamento PLA, a CL1 comportou-se bem, sem que as peças oriundas desse material apresentassem derretimento, esmagamento, desprendimento da mesa ou distorçôes nas camadas impressas. No entanto, nas configurações, a Velocidade de Impressão não pôde ultrapassar os $100 \%$, com riscos de que se obtivesse uma peça de baixa qualidade e resistência. Depois de finalizados todos os testes ofilamento do tipo PLA foi 
escolhidopara originar os protótipos.

Na Figura 6 são mostrados dois conjuntos de peças: um impresso em PLA e outro em ABS (com variaçôes de densidade entre 12\% e 100\%). Evidenciandoseque as camadas do $\mathrm{ABS}$ não são homogêneas. Muitas das vezes isso ocorre por não estarem corretamente depositadas umas sobre as outras.

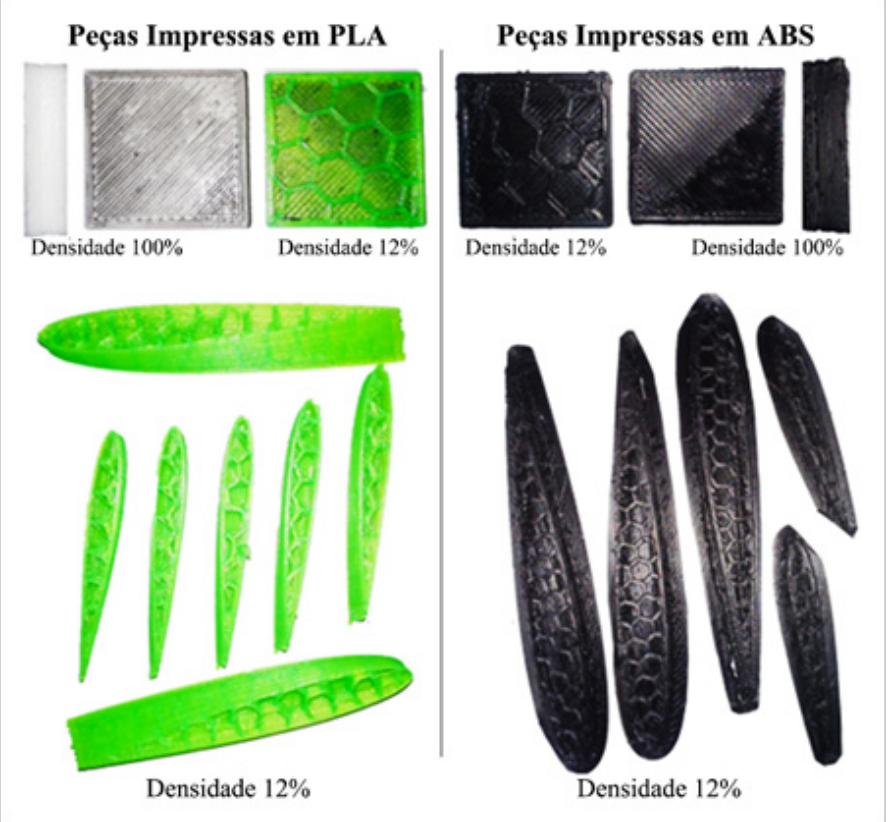

Figura 6. Peças impressas em PLA e ABS

\section{Calibração da impressora}

Os testes na calibragem normal da impressora mostraram-se capazes de gerar bons resultados para as peças posicionadas no centro da bandeja de vidro, no entanto quando desejou-se imprimir várias peças de uma única veztornou-se indispensável que seefetuasse uma calibragem manual nos parafusos da bandeja de impressão, a fim de nivelá-laem todos os pontos.

O produto final originado da impressão de diversas peças ao mesmo tempo (Figura 7)apresentou uma resolução menor do que a visualizada na impressão individual. Isso aconteceu pelo fato de o bico extrusor percorrer um caminho vazio entre peças deixando nesse percurso uma fina camada de material, a qual aumentou a aspereza das peças prototipadas demandando intervenção com tesoura e lixa para obter-se um produto final satisfatório. Para superar esse problema a Velocidade de Impressão foi mantida entre $90 \%$ e, no máximo, $100 \%$. Outro fato que se tornou relevante para a escolha da impressão de múltiplas peçasfoi o,considerável, aumento no tempo de impressão.

\section{Impressão remota}

Para os testes de impressão remota dedicaram-se 21 horas. Nesse período foram impressas 28 peças reservas, sendo que 27 dessas eram peças sobressalientes para uma possível quebra das pás e 1 Centro (bub).

A impressão por meio desse artifício se mostrou eficaz, porém continuou sendo indispensável a ação humana no processo. Haja visto que era necessário preparar a bandeja de vidro e esperar algumas camadas para confirmar o êxito no início do processo. Assim como, quando se findava a prototipagem, era necessário que se fizesse a remoção das peças manualmente. Somava-se a isso, que não se conseguia resolver falhas por meio virtual, e caso, no decorrer do processo ocorresse algum erro era necessário recomeçar a impressão presencialmente.

Afim de evitar gastos desnecessáriosde filamento num processo errôneoinstalou-se uma webcampara, além do acompanhamento via Cliever Lab (Pro), também visualizar-se a impressão diretamente na impressora, possibilitando a interrupçáodo processo à distância,caso se observasse algum problema. Isso fez-se necessário pois, mesmo ao apresentar erros (desprendimento, falta de aderência, deformaçóes, etc.), a impressora náo interrompia o andamento do trabalho e isso resultava em perda de tempo, extravio de material e peças inúteis.

Para fins deste trabalho, apenas as peças reservas foram impressas com acompanhamento remoto. Todas as demais foram impressas com acompanhamento presencial, para possibilitar que se descrevesse as análises apresentadas e também pelo pouco tempo disponível para erros.

Outro problema superado com o acompanhamento remoto da impressão foi o relacionado ao ruído constante emitido pela máquina, o qual podia causar alguns transtornos (dor de cabeça, por exemplo). Por essa razão torna-se ideal que, sempre que possível, opte-se por monitorar a impressão remotamente.

\section{Materiais utilizados para reduzir a rugosidade e aumentar a resistência}

A fim de conhecer-se o equipamento, o aspecto do produto final e a capacidade de impressão da CL1 

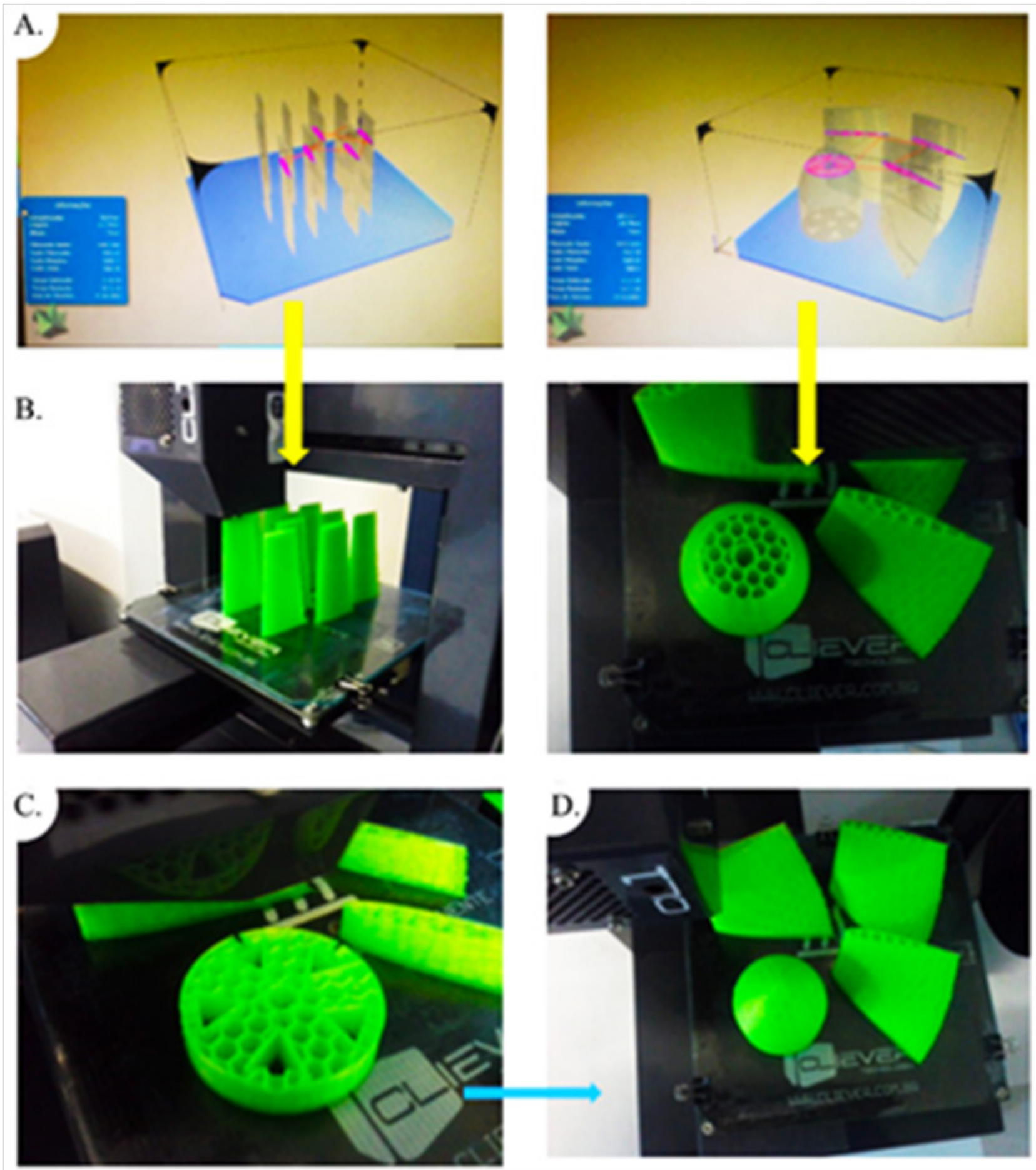

Figura 7. Impressão de múltiplas peças: A. Vistas na bandeja virtual; B. Vistas na bandeja de vidro; C.Decorridos 90 minutos; e D. Após 13 horas de impressão

primeiramente imprimiu-se uma peça-teste (Figura 8). Para essa primeira impressão destinaram-se 4 horas e 28 minutos e o produto dela foi utilizadocomo análise inicial para a tomada de decisão quanto a imprimir-se inloco.

$\mathrm{Na}$ Figura 8 destacam-se ainda as partes do perfil aerodinâmico NACA 0012 e o formato interno da peça-teste impressa. Esse formato foi gerado de acordo com a densidade escolhida.As divisôes hexagonais internasna peça (forma de "colmeia")foram definidas automaticamente pelo software da impressora.

Após esta análise prévia bem-sucedida, decidiu-se por imprimir seis peças-testes de variadas geometrias, as quais após unidas deram origem a duas pás,que por sua vezforamtestadas com diversos materiais visando-se aumentar a resistência e reduzir a rugosidade ao ponto de que esta não tenha, ou exerça pouca, influência na aerodinâmica das pás. Esta análise foi a última feita 


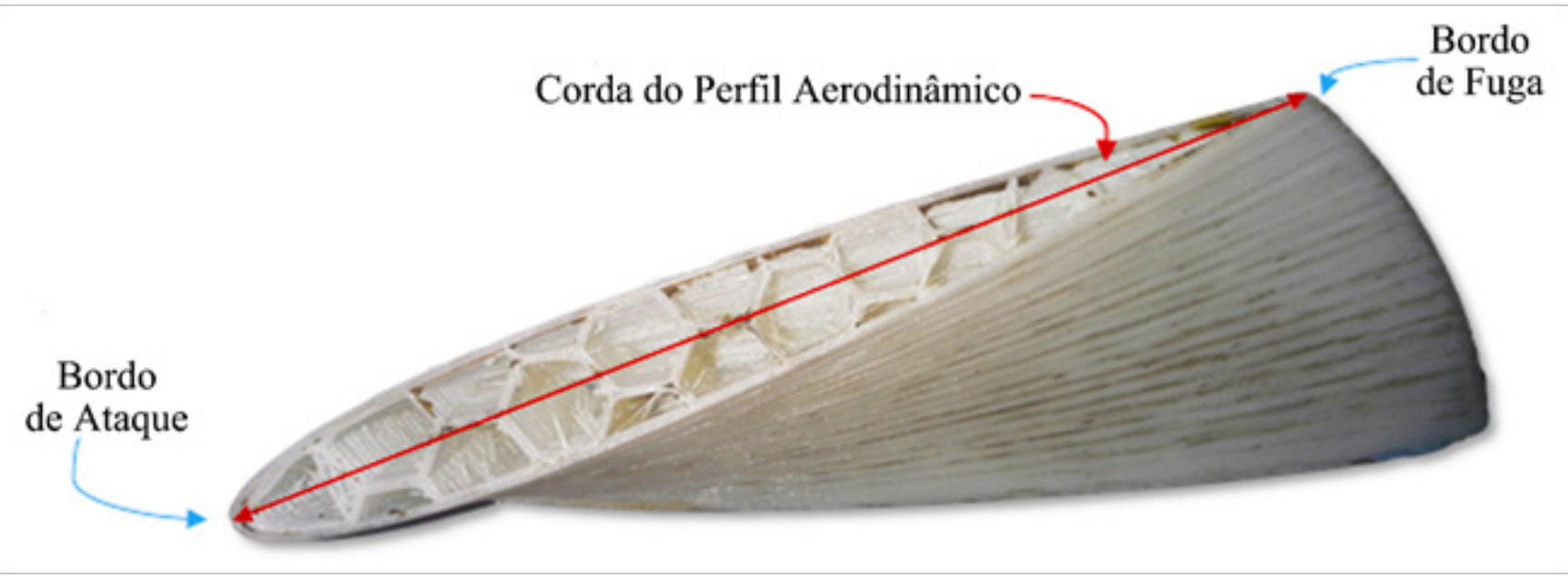

Figura 8.Peça-teste. Estrutura interna da peça-teste de $50 \mathrm{~mm}$ e partes do perfil aerodinâmico NACA 0012

antes de expor-se as peças prototipadas ao escoamento de ar do túnel aerodinâmico Professor Debi Pada Sadhu do Laboratório de Mecânica dos Fluídos da Universidade Federal do Rio Grande do Sul - LMF/ UFRGS.

Para impressão destas seis peças-teste foram necessárias 14 horas e 23 minutos, sendo que dessas, 9 horas e 47 minutos foram para as peças da base e do meio (densidade 12\%) e 4 horas e 36 minutos para as peças do topo (densidade 100\%). As peças do topo necessitaram ser impressas sólidas (densidade 100\%) por apresentarem pouca resistência quando impressas parcialmente ocas, isso se deu por possuírem um volume muito pequeno e pouca curvatura.

Após impressas, as peças foram unidas e levemente lixadas. Além do tratamento com lixa, para os testes de rugosidade e resistência, aplicaram-se outros diferentes tipos de materiais. A lista completa e os resultados obtidos são descritos a seguir:

- Lixa-Reduziu significativamente a rugosidade das pás. No entanto, ainda se observourugosidade sensível ao toque, a qual não foisignificativa nos resultados obtidos, posteriormente, com os testes das características aerodinâmicas;

- Esmalte sintético - Reduziu um pouco mais a sensação da rugosidade ao toque. Porém aumentou o peso da peça modificando a aerodinâmica;

- Verniz para madeira - Reduziu consideravelmente a rugosidade. Porém, aumentou muito o peso final da peça;

- Massa adesiva epóxi - Reduziu a rugosidade em níveis maiores que o verniz. Em contrapartida, precisou ser lixada e ainda assim o peso final mostrouse maior que o verniz. Outra dificuldade apresentada foi a aplicabilidade do material sobre a superfície da pá, pois, além da aderência ser dificultosa, tornou-se impossível garantir a homogeneidade da espessura da camada ao longo de toda a pá. Esse tipo de material também aumentou a resistência das pás;

- Tratamento com vapor de acetona - Este tratamento é indicado para peças impressas com ABS e consta de colocar-se a peça em um recipiente com acetona líquida (de preferência pura). Em seguida aquece-se o recipiente até que o processo de evaporação se inicie. Após 10 minutos de exposição, a superfície começa a derreter e homogeneíza-se totalmente, tornando-se lisa. Porém com o PLA esse processo químico foiineficaz, pois suas propriedades diferem do ABS e, portanto, não reagem com a acetona;

- Cola de isopor - Mostrou-se eficaz para reduzir a rugosidade. No entanto, ao secar evidenciaram-se bolhas na superfície e aumento no peso da peça;

- Cola de isopor combinada com papel filme PVC - Resultou em uma superfície lisa. Porém, o processo foi demorado e seu resultado incerto. A resistência do material foi aumentada, mas não a níveis de justificar a escolha desse trabalhoso método;

- Adesivo plástico para PVC - Ineficaz, pois não gerou quase nenhuma diferença na rugosidade $\mathrm{e}$ resistência da peça após a aplicação de 3 camadas;

- Papel contact - Material que demonstrou o melhor resultado, pois não demandou muito tempo de aplicação e resultou em uma superfície muito lisa e resistente, modificando muito pouco a espessura da 
pá. No entanto tornou-se aerodinamicamente ineficaz, pois apresentou problemas no acabamento final sobre o bordo de fuga da pá.

Sendo assim, após os testes com os diferentes materiais (Figura 9), optou-se por aplicaro tratamento com lixa de diferentes granulaçóes nas peças. O melhor resultado para o trato com lixa foi verificadoutilizandose lixa \#120 para ferro,pelo acabamento grosseiro após finalizada a prototipagem 3D. Em seguida, refinavase com lixas médias para madeira (granulação 200 e 240)e finalizava-se o processo com lixa d'água \#500. Esse processo não reduziu totalmente a rugosidade das peças, no entantodiminuiu desejavelmente sua interferência aerodinâmica.Todo o processo para as 10 pás demandou aproximadamente 10 horas de lixamento. Os dois conjuntos originários da prototipagemforam montados e testados em túnel aerodinâmico.

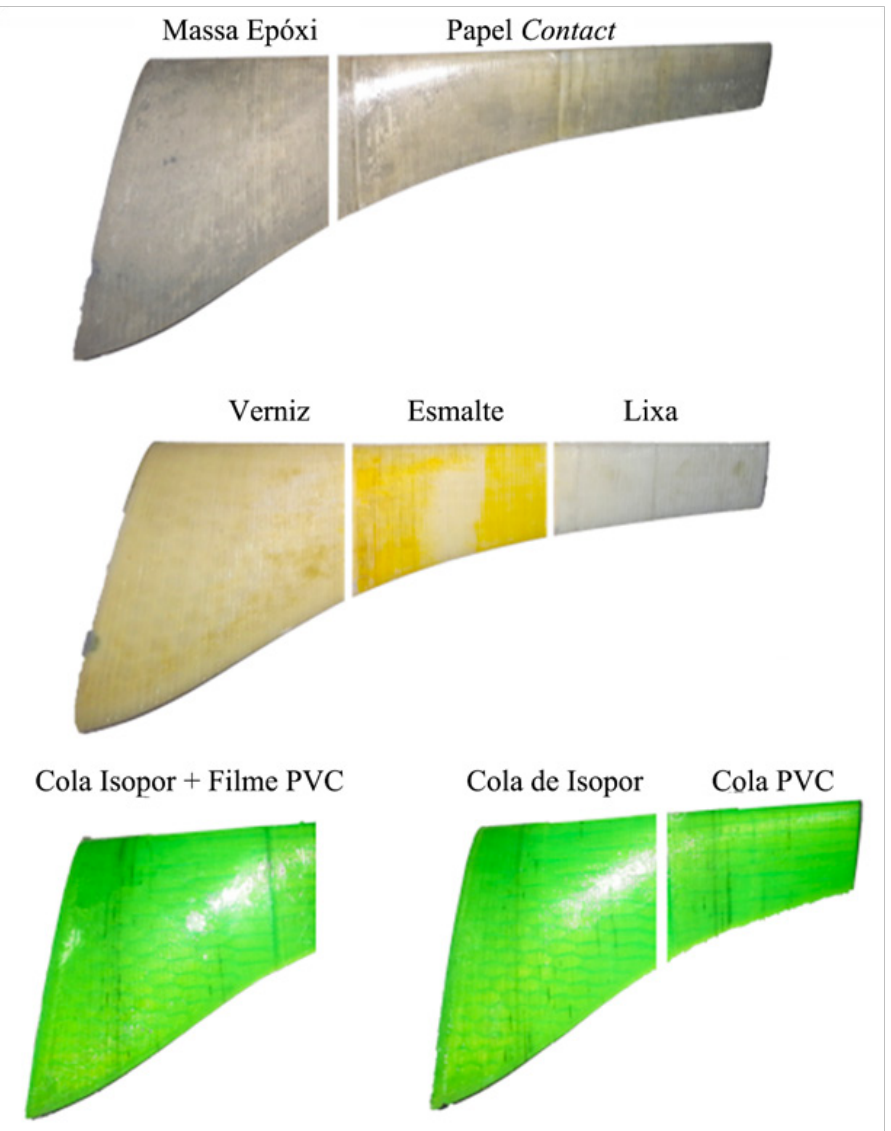

Figura 9. Peças acabadas com diferentes tipos de materiais

Os testes efetuados no túnel analisaram o comportamento dos protótiposquando expostos a diferentes velocidades do escoamento de ar $(1 \mathrm{~m} / \mathrm{s}$ - 9,4 m/s). Através deles apontou-se uma falha no desempenho do protótipo com Pás Ótimas de Betz
Modificada (Figura 10A) que cisalhou quando exposto a uma velocidade de ar de $9 \mathrm{~m} / \mathrm{s}$. Com as peças reservas impressas montou-se um novo protótipo e procedeuse novamente os mesmos testes, sendo que dessa vez o protótipo com Pás Ótimas de Betz Modificadas resistiu bem ao máximo escoamento de ar do túnel. Nesse contexto não foipossível precisar o que ocasionou a falha, mas dois agentes surgiram como principais suspeitos: falha no processo de prototipagem e/ou falha no processo de montagem. Já o protótipo com Pás Ótimas de Betz (Figura 10B), por ser mais robusto, nada sofreu.

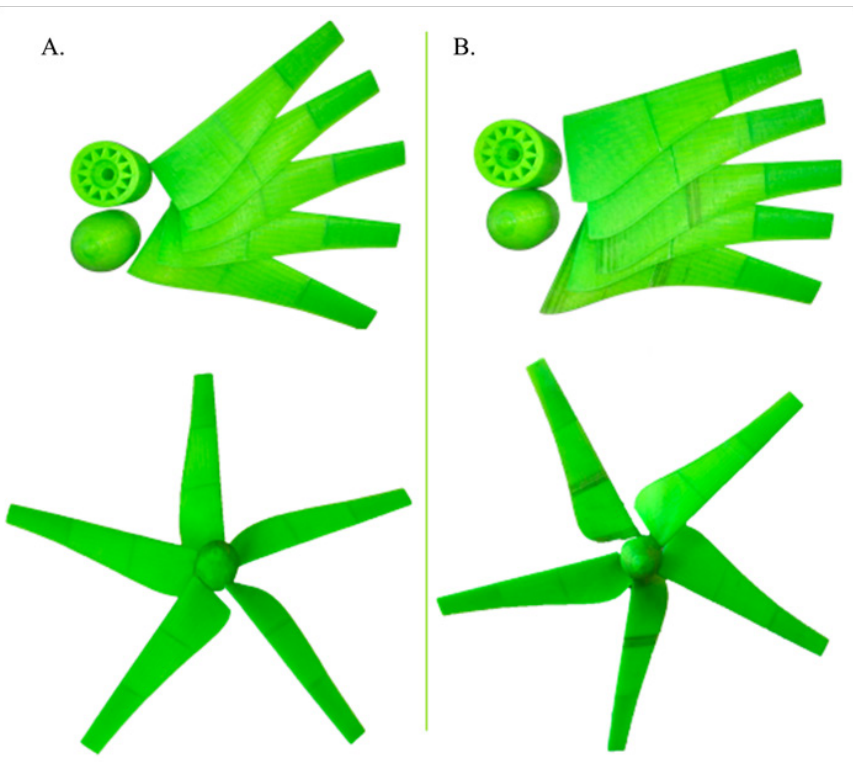

Figura 10. Protótipos: A. Com Pás Ótimas de Betz Modificadas; e B. Com Pás Ótimas de Betz

Após toda a análise descrita, os dois protótipos foram aprovados e seguiram para os testes de desempenho aerodinâmico. Os resultados obtidos por Garré (2015) com os testes de RPM, Torque Estático, Torque Dinâmico, Perfil Aerodinâmico, Tipos de Pás, entre outros, contribuíram para a tomada de decisáo acerca da construção de um aerogerador de pequeno porte que será concebido em escala real.

\section{Tempo de impressão, peso das peças e custos}

O processo de impressão dos protótipos necessitou de 100 horas para ser concluído, e resultou em um gasto final de $480 \mathrm{~g}$ de filamento, sendo que desses, $255 \mathrm{~g}$ foram para o protótipo com Pás Ótimas de Betz e 225 g para o com Pás Ótimas de Betz Modificadas.

$\mathrm{O}$ processo de testes resultou em 80 horas de 
impressão e as 28 peças reservas (sendo 27 peças sobressalientes para uma possível substituição nas pás e 1 centro) demandaram mais 21 horas e no total pesaram $342 \mathrm{~g}$.

Logo, no total foram necessárias 201 horas de impressão, $822 \mathrm{~g}$ de filamento, resultando num gasto total de R\$ 1.005,00 considerando os testes, peças reservas, protótipos e o custo de operação da máquina.

Assim, levando-se em consideração apenas a impressão dos protótipos, pôde-se dizer que o custo do processo de prototipagem $3 \mathrm{D}$ foi quase vinte vezes menor do que o menor orçamento dentre as empresas especializadas (Tabela 1). Ainda se considerado todo o gasto (testes, peças reservas e protótipos), essa diferença decresceu para a metade, ou seja, foi cerca de dez vezes menor.

Tabela 1. Orçamento das empresas especializadas em prototipagem 3D.

\begin{tabular}{|l|l|}
\hline Empresa 1 & $\mathrm{R} \$ 9.600,00 *$ \\
\hline Empresa 2 & Entre $\mathrm{R} \$ 9.920,00$ a $\mathrm{R} \$ 18.680,00^{*}$ \\
\hline Empresa 3 & $\mathrm{R} \$ 9.264,00 *$ \\
\hline
\end{tabular}

*Levantamento feito no período compreendido entre 07/2015 a 09/2015.

\section{CONCLUSÃO}

A prototipagem 3D administrada neste trabalho possibilitou a geração de perfis com alto grau de fidelidade estrutural e aerodinâmico o que garantiu a confiabilidade dos dados medidos e confirmou a possibilidade de se imprimir peças de alta complexidade a partir de impressoras 3D de pequeno porte. No que diz respeito aos custos, com exceção dos casos que se necessite de alta resolução na peça finalizada, aconselha-se a aquisição de um equipamentoao invés da terceirizaçãodo serviço de impressão, o qual mostrou-se demasiadamente caro.

A tecnologia abordada no presente estudo mostrouse capaz de ser utilizada para gerar as pás de um protótipo eólico. Resultando num produto final capaz de simular as açóes de um equipamento real. Num comparativo entre os dois protótipos, o confeccionado com Pás Ótimas de Betz Modificadas recebeu 12\% a menos de material (filamento PLA) que o montado comPás Ótimas de Betz, resultando numa turbina mais leve, porém mais frágil.
As limitaçóes da impressora ficaram por conta dotipo de material escolhido. Caso o filamento do tipo ABS fosse escolhido para a impressão não se conseguia um bom produto final,evidenciando-se a necessidade de escolha pelo filamento do tipo PLA.

$\mathrm{Na}$ análise do Cliever Lab (Pro) as funcionalidades são intuitivas e de fácil compreensão. Os equívocos notados foramoriginados por alguns erros de cálculonas variáveis Tempo restanteeHora de término, o que fez o operador errar no planejamento do tempo de impressão do projeto. Um outro tipo de informaçáo que seria útil nesse tipo de software é o peso final da peça, ausente na versão 3.1 .

Após finalizados todos os testes, compreendidos em 200 horas de impressão,gerou-se um manual de procedimentos o qual foi disponibilizado à comunidade em gerale também enviado ao fabricante.

A intenção final desse trabalho é decontribuir com as futuras pesquisasque envolvam esse equipamento ou impressoras 3D de tecnologia semelhante.

\section{AGRADECIMENTOS}

À Coordenadoria de Aperfeiçoamento de Pessoal CAPES pelo aporte financeiro.

Ao Programa de Pós-Graduação em Engenharia Mecânica - PROMEC da UFRGS por ter disponibilizado a estrutura necessária para desenvolver a fase experimental.

Ao Projeto de Pesquisa "Sistema para Microgeração Eólica com Eficiência e Segurança”, aprovado pelo Conselho Nacional de Desenvolvimento Científico e Tecnológico - CNPq, coordenado pelo professor Ály Ferreira Flores Filho do Programa de Pós-Graduação em Engenharia Elétrica - PPGEE da UFRGS, o qual custeou a prototipagem das peças testadas.

\section{REFERÊNCIAS}

ABNT - Associação Brasileira de Normas Técnicas.NBR IEC61400.1: Requisitos de projeto. Especifica os requisitos de projeto para assegurar a integridade de engenharia dos aerogeradores. Rio de Janeiro, 2008.

ACUNHA, I. Análise do desempenho de um aerogerador de pequeno porte. Dissertaçáo (Mestrado em Engenharia Oceânica). Rio Grande: FURG, 2006.

AKWA, J. Análise Aerodinâmica de turbinas eólicas Savonius empregando dinâmica dos fluidos computacional. Dissertaçáo(Mestrado em Engenharia Mecânica).Porto Alegre: PROMEC, UFRGS, 2010. 
ÁLY, F.F.F., PETRY, A. P., LOUREIRO, L.T.R.;HOMRICH,R. P.; ITURRIOZ, I.; MÖLLER, S. V. Projeto de pesquisa de umsistema para microgeraçáo eólica com eficiência esegurança. Disponível em:<http://www.cnpq.br/web/guest/projetospesquisa?p_auth=yePywO49\&p_p_id=pesquisaapoioportlet_ WR_pesquisacnpqportlet_=enviarDados $>$. Acesso em: 20 dejun. 2016.

ANSI - American National Standards Institute. IEC614002: Design requirements for small wind turbines. Trata dos aspectos de segurança, garantia de qualidade e integridade de engenharia e especifica os requisitos para a segurança em aerogeradores de pequeno porte, incluindo design, instalação, manutenção e funcionamento em condições externas. Genebra, Suíça, 2013.

BURTON, T.; SHARP, D.; JENKINS, N.; BOSSANYI, E.Wind Energy Handbook. John Wiley \& Sons ltd., Toronto, 2001. CLIEVER. Suporte técnico online. Disponível em: <https:// www.cliever.com.br/ p/suporte>. Acesso em 25 de set 2015. DEURSEN, F.V.; BERNARDO, A.A revoluçáo das impressoras 3D.Revista Super Interessante, n.314, p. 31-32, ed. Abril, São Paulo, 2013.

FERNANDES A.V.S.; MOTA F.A.O. Impressoras 3D: Uma compreensão da evolução e utilização. In: IX Simpósio de Informática.Anais....Montes Claros, MG, Brasil, 2016.

FRANCO, L. F. L. Estudo experimental de um rotor Savonius com estator.Monografia. Engenharia Mecânica, UFRGS, 2013. GARRÉ, S.O.Avaliação experimental do desempenho aerodinâmico de pequenas turbinas eólicas confeccionadas em prototipagem 3D.Dissertaçáo(Mestrado em Engenharia Mecânica).Porto Alegre: PROMEC, UFRGS, 2015.

GARRÉ,S.O.; PETRY,A.P.; DE PAULA, A.V.; ROSALES, J.L.; JODAR, T.D. Experimental evaluation of the aerodynamicperformance of turbines small wind confectioned in prototyping 3D. In: 23rd ABCM - International Congress ofMechanical Engineering. COBEM: Anais...Rio de Janeiro RJ, Brasil,2015.

GASCH, R.; TWELE, J.; Wind power plants. Fundamentals, design, construction and operation.Springer Heidelberg Dordrecht London New York, 2002. 548 p. ISBN: 978-3-64222937-4.

GREGG, J.R. Design and experimental testing of small-scale wind turbines.Dissertaçáo(Mestrado em Engenharia Mecânica). Texas: Universidade de Baylor, 2011.

PANKIEWCZ, I. Como funciona a impressora 3D. Disponível em: <http://www.tecmundo.com.br/impressora/2501-comofunciona-a-impressora-3d-.htm>. Acesso em: 10 set. 2016.

HORN, D. Análise numérica da esteira aerodinâmica formada por uma turbina eólica com dimensionamento ótimo de Betz. Dissertaçáo(Mestrado em Engenharia Mecânica).Porto Alegre: PROMEC, UFRGS, 2010.
LUDWIG, D. Análise numérica da influência de fatores atmosféricos na esteira aerodinâmica de turbinas eólicas. Dissertaçáo(Mestrado em Engenharia Mecânica).Porto Alegre: PROMEC, UFRGS, 2011.

PATRIOZOTTO, R.R. Análise e viabilidade técnica de implantação de aerogeradores eólicos de pequeno porte. Tese(Doutorado em Engenharia de Energia na Agricultura). Cascavel: Universidade Estadual do Oeste do Paraná, 2012.

PEREIRA, I.Q.G. Condições de viabilidade da microgeração eólica em zonas urbanas. Dissertaçáo (Mestrado em Engenharia Mecânica). Universidade do Porto, 2010.

PRADO, L.F.B.Projeto de aerogerador para residências sem acesso à rede de energia elétrica. Disponível em: $<$ http://sites. poli.usp.br/d/pme2600/2010/Artigos/Art_ TCC_036_ 2010. pdf $>$. Acesso em: 27 de novembro 2016.

ROCHA, P.A.C.; CARNEIRO, F.O.; LOPES, A.S.; MAIA, I.A.; MODOLO, A.B.Montagem e testes de uma bancada para mediçáo de desempenho de aerogeradores em escala. Revista Brasileira de Ensino de Física, v. 32, n. 2, 2309.Fortaleza - CE, Brasil, 2011.

REISDORFER, T. As diferentes tecnologias de impressáo 3D.Disponível em: <http://www.impressao3dfacil.com.br/ diferentes-tecnologias-de-impressao-3d/>.Acesso em: 15 set. 2016.

SILVEIRA, D.P.Como funciona e como surgiu a impressora 3D. Disponível em: <https://www.oficinadanet.com.br/ post/11352-como-funciona-e-como-surgiu-aimpressora-3d >. Acesso em: 8 set. 2016.

SILVA, G.B.O. Desenvolvimento de uma turbina eólica de eixo vertical.Dissertação(Mestrado em Engenharia).Universidade Técnica de Lisboa, 2012.

SONG, Q. Design, fabrication, and testing of a new small wind turbine blade.Dissertaçáo(Mestrado em Engenharia). Universidade de Ghelph, 2012.

TAKAGAKI, L.K.Tecnologia de impressáo 3D.Revista Inovação Tecnológica. v.2, n. 2, p.28-40.São Paulo,2012.

TEIXEIRA A.R. Micro - turbinas instaladas em ambiente urbano para aplicaçóes de microgeração: desenvolvimento de uma metodologia para identificação e caracterização do potencial eólico.Dissertaçáo(Mestrado em Engenharia da Energia e do Ambiente). Universidade de Lisboa, 2010.

VERDUM, V. Projeto de um aerogerador com segurança inerente para aplicação urbana.Dissertaçáo(Mestrado em Engenharia Elétrica).Porto Alegre: PPGEE, UFRGS,2013.

WENZEL, G.M. Projeto aerodinâmico de pás de turbinas eólicas de eixo horizontal.Monografia. FENG, PUCRS, 2007. 